\title{
Tunneling effect in 1,5 H-migration of a prototypical •OOQOOH
}

\author{
Yuan Sha and Theodore S. Dibble* \\ Chemistry Department, SUNY-Environmental Science and Forestry, Syracuse, NY 13210 USA \\ $\underline{\text { Abstract }}$ \\ Propane is the smallest molecule that can serve as a model of the chemistry of diesel autoignition. \\ Diesel autoignition requires $\mathrm{H}$-migration reactions of the type $\cdot \mathrm{OOCH}_{2} \mathrm{CH}_{2} \mathrm{CH}_{2} \mathrm{OOH} \rightarrow$ \\ $\mathrm{HOOCH}_{2} \mathrm{CH}_{2} \mathrm{C} \cdot \mathrm{HOOH}$. Previous studies of this type of $\mathrm{H}$-migration reactions accounted for \\ tunneling (through-barrier processes) using 1-D models of the reaction coordinate, namely, the \\ Eckart or Wigner approximations. Here we present the first study to use multi-dimensional \\ approaches, specifically, small- and large-curvature tunneling, to treat through-barrier processes. \\ Calculations are carried out using the POLYRATE program and make use of the M05-2X/6- \\ $31+\mathrm{G}(\mathrm{d}, \mathrm{p})$ level of theory.
}

Keywords: OOQOOH, combustion, tunneling,

* FAX: 315-470-6856, tsdibble@esf.edu 


\section{Introduction}

Researchers are trying to better understand the molecular mechanisms of combustion, both to improve current engine designs and design new fuel/engine combinations. ${ }^{1,2,3,4}$ In diesel engines and some novel engines, such as homogeneous charge compression ignition (HCCI) engines, ignition occurs due fuel exposure to high temperatures in the absence of a spark. As a result, ignition is controlled by chemistry, specifically, the competition between radical chain propagation and branching versus chain termination. ${ }^{5}$ The critical reactions in autoignition chemistry are displayed in Figure 1, using propane as a model fuel. A recent paper illustrates how the stages of autoignition chemistry can be understood, using propane as an example. ${ }^{6}$

The effectiveness of chain propagation and branching versus termination depends critically on the fate of peroxy radicals $(\mathrm{ROO} \bullet)$, hydroperoxyalkyl radicals $(\cdot \mathrm{QOOH})$, and hydroperoxyalkylperoxy radicals $(\cdot \mathrm{OOQOOH})$. Experimental determination of rate constants for these radicals is challenging. To date, only one $\cdot \mathrm{QOOH}$ species has been monitored experimentally, ${ }^{7}$ and there has never been any experimental detection of any $\bullet$ OOQOOH species. The challenge in directly detecting $\cdot \mathrm{OOQOOH}$ comes in part from the complexity of the reaction mixture in which they are formed (often as multiple isomers). In addition, the barrier to 1,n Hshift of $\cdot \mathrm{OOQOOH}$ tends to lie lower in energy than the $\mathrm{O}_{2}+\cdot \mathrm{QOOH}$ entrance channel, allowing for chemically activated loss of $\cdot \mathrm{OOQOOH}$. As a result, the experimental basis of our present understanding of autoignition chemistry depends largely on efforts to quantity the yield of stable products and small radicals $(\bullet \mathrm{OH} \text { and } \mathrm{HOO} \bullet)^{5}$ As a result, computational chemistry has played, and will continue to play, a large role in expanding our understanding of autoignition chemistry. 
One of the key steps in autoignition chemistry is an H-migration reaction of $\bullet \mathrm{OOQOOH}$ species. This class of reactions has not received as much attention from theorists as the analogous $\mathrm{H}-$ migration reactions of peroxy radicals. In particular, the role of tunneling in these reactions has never been studied rigorously. We previously studied tunneling in the reactions of 1propylperoxy radical, which is the prototype for $1,5 \mathrm{H}$-migration in peroxy radicals. ${ }^{8}$ In the present paper we investigate tunneling in the analogous 1,5 H-migration reaction of - $\mathrm{OOCH}_{2} \mathrm{CH}_{2} \mathrm{CH}_{2} \mathrm{OOH}$ :

$\cdot \mathrm{OOCH}_{2} \mathrm{CH}_{2} \mathrm{CH}_{2} \mathrm{OOH} \rightarrow\left[\mathrm{HOOCH}_{2} \mathrm{CH}_{2} \mathrm{C} \cdot \mathrm{HOOH}\right] \rightarrow \mathrm{HOOCH}_{2} \mathrm{CH}_{2} \mathrm{CH}=\mathrm{O}+\cdot \mathrm{OH}$

Reaction (1) is part of the chain propagation/branching pathways indicated in Scheme 1. The competing chain termination reaction to produce $\mathrm{HOO} \bullet+\mathrm{CH}_{2}=\mathrm{CHCH}_{2} \mathrm{OOH}$ has a barrier which is $8-10 \mathrm{kcal} / \mathrm{mol}$ higher in energy. ${ }^{9}$ The presence of the $-\mathrm{OOH}$ group lowers the barrier to $1,5 \mathrm{H}-$ shift by $\sim 4 \mathrm{kcal} / \mathrm{mol}$ as compared to that in 1-propylperoxy radical. ${ }^{8,9}$ As indicated in Reaction 1 , the radical product of this 1,5 H-migration will fall apart to hydroxyl radical plus a ketohydroperoxide. This radical product is absolutely unstable or only slightly metastable with respect to O-O scission. ${ }^{10,11}$ This appears to be true of $\alpha$-hydroperoxyalkyl radicals, generally, ${ }^{12}$ including some oxygen-substituted variants. ${ }^{13,14}$ The barrier height to reaction (1) has been computed in previous work, ${ }^{10,11,15}$ and Goldsmith et al used Born-Oppenheimer Molecular Dynamics to study the energy distribution of the products of this reaction. ${ }^{15}$

Previous studies of the kinetics of $\mathrm{H}$-migration reactions in •OOQOOH (e.g., Refs. 9, 10, and 11) only considered tunneling in the Eckart ${ }^{16,17}$ or Wigner ${ }^{18}$ approximations. The present work is focused on determining the reliability of those approaches, using multi-dimensional tunneling to obtain more reliable tunneling coefficients. The next section presents the methods used to characterize the potential energy surface and calculate tunneling corrections to the thermal rate 
constants. We next discuss the structures and energetics of this system. This is followed by a presentation and analysis of the results of tunneling calculations. We conclude with some recommendations for the tunneling calculations in studies of peroxy radical chemistry in combustion.

\section{Materials and Methods}

The GAUSIAN09 ${ }^{19}$ system of programs was used to obtain geometries, energies, and vibrational frequencies of all species. As computing the tunneling correction requires repeated calculation of the Hessian matrix, it is necessary to use a computationally efficient method for characterizing the system: usually, density functional theory. Here we used the M05-2X ${ }^{20}$ level of theory with a $6-31+\mathrm{G}(\mathrm{d}, \mathrm{p})$ basis set. The spin unrestricted formalism was used for radicals. Harmonic vibrational frequencies were computed using analytical gradients. Calculations used the default convergence criteria and grids in GAUSIAN09.

The Wigner tunneling correction, $\kappa_{\text {Wigner }}(T)$, to the classical rate constant was computed using the formula:

$$
\kappa(T)=1+\frac{1}{24}\left(\frac{h v^{*}}{k_{B} T}\right)^{2}
$$

where $h$ is Planck's constant, $v^{*}$ is the imaginary vibrational frequency, and $k_{\mathrm{B}}$ is Boltzmann's constant. The asymmetric Eckart tunneling correction, $\kappa_{\text {Eckart, }}$ was calculated using numerical integration of the microcanonical tunneling coefficient, $\Gamma(E)$ :

$$
\kappa(T)=\frac{\exp \left(\frac{E_{0}}{k_{B} T}\right)}{k_{B} T} \int_{E=0}^{\infty} \Gamma(E) \exp \left(-\frac{E}{k_{B} T}\right) d E
$$


where $E_{0}$ is the barrier height.

Calculations of multi-dimensional tunneling coefficients were carried out using POLYRATE, ${ }^{21}$ GAUSSIAN09, and the GAUSSRATE ${ }^{22}$ interface between these two programs. The minimum energy path (MEP) was optimized with a reaction path of $-0.8 \AA<s<0.8 \AA$ by using the PageMcIver integrator with a step size of $0.0025 \AA$. Zero-, small- and large-curvature tunneling calculations ${ }^{23}$ (ZCT, SCT, and LCT, respectively) were carried out to determine the corresponding tunneling corrections: $\kappa_{\mathrm{ZCT}}(T), \kappa_{\mathrm{SCT}}(T)$, and $\kappa_{\mathrm{LCT}}(T)$. In addition, the effects of large- and small-curvature tunneling were combined to determine the microcanonically optimized multidimensional tunneling correction, $\kappa_{\mu \mathrm{OMT}}(T) . \kappa_{\mu \mathrm{OMT}}(T)$ is determined using the larger of the microcanonical tunneling coefficients, $\Gamma_{\mathrm{SCT}}(E)$ or $\Gamma_{\mathrm{LCT}}(E)$, in equation (3). In the above calculations, the vibrational frequencies were scaled by factor of $0.975 .{ }^{24}$

Sharma et al $^{10}$ reported that proper treatment of the effects of hindered rotors on rate constants in Reaction (1) is complicated by the existence of intramolecular hydrogen bonds. These hydrogen bonds cause the hindered rotations to be non-separable, which means the partition function of the reactant cannot be properly determined using standard methods for hindered rotors. Because of this complication, we do not calculate rate constants; instead we focus on tunneling corrections to the rate constant. The multi-structural transition state theory of Truhlar and coworkers ${ }^{25}$ could be used to compute reliable rate constants, but such calculations are beyond the scope of this study.

\section{Results and Discussion}


The structures of the reactant, saddle point, and products are shown in Figure 2. The saddle point structure shown in Figure 2 is an enantiomer of that reported by Goldsmith et al, ${ }^{11}$ which is the lowest energy saddle point at the CBS-QB3 ${ }^{26}$ level of theory. The saddle point possesses a quasicyclic structure (six-membered ring) formed by $\bullet \mathrm{O}-\mathrm{O}-\mathrm{C}-\mathrm{C}-\mathrm{C}-\mathrm{H}$. Conformers of the reactant have been discussed by Sharma et al. ${ }^{10}$ According to their work, the most stable conformers of the reactant have quasi-cyclic structures formed by $\mathrm{OH}-\mathrm{O}$ hydrogen bonds. The conformer shown in Figure 2 is the one from which the 1,5 H-migration can occur directly; in other words, it is the one connected to the saddle point by the MEP. It does not possess an intramolecular $\mathrm{OH}-\mathrm{O}$ hydrogen bond, but does possess something like the six-membered $\bullet$ O-O-C-C-C-H ring of the saddle point.

On the products side, the MEP connects to $\mathrm{HOOCH}_{2} \mathrm{CH}_{2} \mathrm{C} \cdot \mathrm{HOOH}$. The $\mathrm{HOOCH}_{2} \mathrm{CH}_{2} \mathrm{C} \cdot \mathrm{HOOH}$ product forms an eight-membered ring with an $\mathrm{OH}-\mathrm{O}$ hydrogen bond, analogous to the structure of one of the low-energy conformers of the reactant. Attempts to scan the $\mathrm{HOOCH}_{2} \mathrm{CH}_{2} \mathrm{C} \cdot \mathrm{HO}-\mathrm{OH}$ distance to obtain the saddle point for formation of $\mathrm{HOOCH}_{2} \mathrm{CH}_{2} \mathrm{CH}=\mathrm{O}$ $+\cdot \mathrm{OH}$ failed; instead the energy abruptly decreased by tens of $\mathrm{kcal} / \mathrm{mol}$ after a small increase in this internuclear distance. We also find certain conformers of $\mathrm{HOOCH}_{2} \mathrm{CH}_{2} \mathrm{C} \cdot \mathrm{HOOH}$ to be absolutely unstable, as shown by the fact that optimization led to production of a hydrogenbonded $\mathrm{HOOCH}_{2} \mathrm{CH}_{2} \mathrm{CH}=\mathrm{O}-\cdot \mathrm{OH}$ complex. For completeness, we also optimized the structure and determined the vibrational frequencies of $\mathrm{HOOCH}_{2} \mathrm{CH}_{2} \mathrm{CH}=\mathrm{O}$ (shown in Figure 2) and $\bullet \mathrm{OH}$. Cartesian coordinates and vibrational frequencies for all species can be found in the Supplementary Material. 
The relative energies for all species are listed in Table 1 . Goldsmith et al. ${ }^{11}$ used QCISD(T) ${ }^{27}$ to obtain energies and extrapolated the QCISD(T) energy to the basis set limit using second order Moller-Plesset perturbation theory. ${ }^{28,29}$ Their work is used here as the benchmark for evaluating the reliability of our relative energies. The present results have a forward barrier height 0.2 lower than the benchmark value. While this close agreement is due, in no small part, to cancellation of errors, it supports the choice of functional and basis set used for this calculation. The energy of $\mathrm{HO} \cdot+\mathrm{O}=\mathrm{CHCH}_{2} \mathrm{CH}_{2} \mathrm{OOH}$ is $4.5 \mathrm{kcal} / \mathrm{mol}$ more positive than the benchmark, but this will be unimportant, as the MEP connects to $\mathrm{HOOCH}_{2} \mathrm{CH}_{2} \mathrm{C} \cdot \mathrm{HOOH}$. One might object that tunneling occurs on adiabatic ground state potential, $V_{a}^{G}$ (the potential energy surface corrected for zeropoint energy), so the existence of a minimum on the MEP is not relevant; however, this radical remains intact as far as we followed the MEP (out to $s=8.9 \mathrm{amu}^{1 / 2} \mathrm{Bohr}$ ).

The imaginary frequency, $v^{*}$, critically influences the tunneling correction because it indicates the sharpness of the barrier. At M05-2X/6-31+G(d,p) we obtain $v^{*}=1782 \mathrm{i} \mathrm{cm}{ }^{-1}$. As a check of the reliability of imaginary frequency, we recalculated the structure and vibrational frequencies of the saddle point at M05-2X with a larger basis set: $6-311+G(2 d f, 2 p)$. The value of $v^{*}=1825 i$ $\mathrm{cm}^{-1}$ obtained with the larger basis set is only $43 \mathrm{i} \mathrm{cm}^{-1}$ larger than that computed at M05-2X/6$31+\mathrm{G}(\mathrm{d}, \mathrm{p})$. While the imaginary frequency is likely rather dependent on the choice of functional or $a b$ initio method, it appears to have little dependence on the basis set when using the M05-2X functional.

A profile of $V_{a}^{G}$, is shown in Figure 3 along with the Eckart fit to the imaginary frequency and potential energy. We should emphasize that the shoulder of $V_{a}^{G}$ at $s \approx+0.2 \mathrm{amu}^{1 / 2} \AA$ does not correspond to the $\mathrm{HOOCH}_{2} \mathrm{CH}_{2} \mathrm{C} \cdot \mathrm{HOOH}$ radical, which lies significantly lower in energy. In 
fact, a similar (if smaller) shoulder appears at the same position in $V_{a}^{G}$ for the 1,5 H-migration of 1-propylperoxy radical. ${ }^{8}$ As is typical, $V_{a}^{G}$ is much broader than the Eckart potential. ${ }^{8,}{ }^{30}$ This leads to the expectation that $\kappa_{\mathrm{ZCT}}$ will be much smaller than $\kappa_{\text {Eckart }}$. Corner-cutting will tend to increase multi-dimensional tunneling coefficients above $\kappa_{\mathrm{ZCT}}$.

The various tunneling corrections are listed in Table 2 over the range 300-1800 K. Figure 4 depicts $\kappa_{\mathrm{ZCT}}$, $\kappa_{\mathrm{SCT}}$, and $\kappa_{\mathrm{LCT}}$ over the temperature range $500-1500 \mathrm{~K}$, a range exceeding that of interest in autoignition chemistry. As $\kappa_{\mathrm{Eckart}}$ and $\kappa_{\mu \mathrm{OMT}}$ nearly equal $\kappa_{\mathrm{SCT}}$ over this range, they are not depicted in Figure 4. At $300 \mathrm{~K}$, the computed tunneling coefficients (except when using the Wigner approximation) are larger than 10 for all methods and span a factor of $\sim 6$. Although $\kappa_{\mathrm{LCT}}$ is always smaller than $\kappa_{\mathrm{SCT}}, \kappa_{\mu \mathrm{OMT}}$ is greater than $\kappa_{\mathrm{SCT}}$ at $\mathrm{T} \leq 500 \mathrm{~K}$. This indicates large curvature tunneling contributes modestly to tunneling at the lowest temperatures (energies) studied here. By contrast, at $700 \mathrm{~K}$ and above, $\kappa_{\mathrm{SCT}}$ equals $\kappa_{\mu \mathrm{OMT}}$ and LCT is not important. The Wigner tunneling corrections are lower than those computed using all other methods until the temperature reaches $700-900 \mathrm{~K} . \kappa_{\text {Eckart }}$ greatly exceeds $\kappa_{\mu \mathrm{OMT}}$ at $300 \mathrm{~K}$, but $\kappa_{\text {Eckart }}$ is nearly

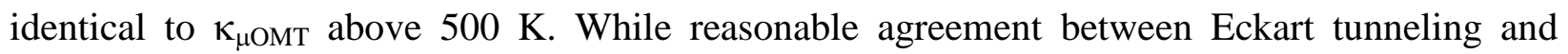
$\mu \mathrm{OMT}$ is not unexpected in light of the past success of Eckart tunneling for $\mathrm{H}$-atom transfer reactions, $8,31,32,33,34$ the closeness of this agreement in this case should be regarded an extreme coincidence.

Recall that $\alpha$-hydroperoxyalkyl radicals such as $\mathrm{HOOCH}_{2} \mathrm{CH}_{2} \mathrm{C} \cdot \mathrm{HOOH}$ may be absolutely unstable on the ZPE-corrected potential energy surface with respect to forming aldehyde $+\cdot \mathrm{OH}$ radicals. This leads to the question: Is it appropriate to treat the product of $\mathrm{H}$-migration of $\cdot \mathrm{OOCH}_{2} \mathrm{CH}_{2} \mathrm{CH}_{2} \mathrm{OOH}$ as $\mathrm{HOOCH} \mathrm{CH}_{2} \mathrm{C} \cdot \mathrm{HOOH}$ rather than $\mathrm{HOOCH}_{2} \mathrm{CH}_{2} \mathrm{CH}=\mathrm{O}+\cdot \cdot \mathrm{OH}$ ? Note 
that $\mathrm{HOOCH}_{2} \mathrm{CH}_{2} \mathrm{C} \cdot \mathrm{HOOH}$ is located as values of $s$ larger than $+0.4 \mathrm{amu}^{1 / 2} \AA$, where the width of the barrier is at least $1.2 \mathrm{amu}^{1 / 2} \AA$. At this large width, tunneling will contribute very little to reaction at even the lowest temperatures relevant to combustion. As a result, the ambiguity about the stability of $\mathrm{HOOCH}_{2} \mathrm{CH}_{2} \mathrm{C} \cdot \mathrm{HOOH}$ should affect tunneling calculations only negligibly.

\section{Conclusions}

Multidimensional tunneling calculations have been carried out, for the first time, for the 1,5 $\mathrm{H}$ migration of an $\mathrm{OOQOOH}$, a reaction which is critical in diesel autoignition chemistry. As expected, small-curvature tunneling dominates, but large-curvature tunneling contributes $\sim 10 \%$ to through-barrier processes at room temperature. At temperatures relevant to combustion chemistry, cancellation of errors leads to a surprisingly good agreement between multidimensional tunneling corrections and those computed with the asymmetric Eckart model. When combined with the success of the Eckart approach for 1-propylperoxy radical, this suggests that the Eckart approximation is a reasonable approach to use, at least above room temperature, to compute tunneling corrections of high-pressure rate constants of $1,5 \mathrm{H}$-shift reactions of peroxy radicals.

\section{Associated Content \\ Supporting Information}

Cartesian coordinates, vibrational frequencies, and absolute energies for all species calculated at the M05-2X level of theory.

\section{Acknowledgements}


This material is based on work was supported by the U.S. Department of Energy, Office of Science, Basic Energy Sciences under Award Number DE-SC0002511. 


\section{Figure Captions}

Figure 1. Radical chain propagation (heavy arrows) and termination reactions of autoignition chemistry starting from 1-propyl radicals. Production of $\mathrm{HO} \bullet+\cdot \mathrm{OCH}_{2} \mathrm{CH}_{2} \mathrm{CH}=\mathrm{O}$ corresponds to chain branching.

Figure 2. The optimized geometries of (a) reactant $\left(\cdot \mathrm{OOCH}_{2} \mathrm{CH}_{2} \mathrm{CHOOH}\right)$; (b) saddle point to 1,5 H-migration of reactant; (c) product $\left(\mathrm{HOOCH}_{2} \mathrm{CH}_{2} \mathrm{C} \cdot \mathrm{HOOH}\right.$ radical); (d) 3hydroperoxypropanal.

Figure 3. Comparison of the asymmetric Eckart potential of Reaction 1 with $V_{a}^{G}$ at M05-2X/6$31+\mathrm{G}(\mathrm{d}, \mathrm{p})$. The Eckart potential energy curve (treating the product as $\mathrm{HOOC} \cdot \mathrm{HCH}_{2} \mathrm{CH}_{2} \mathrm{OOH}$ ) has been shifted upwards so that its barrier height coincides with that of $V_{a}^{G}$.

Figure 4. Tunneling coefficients using small-, large-, and zero-curvature tunneling. As $\kappa_{\text {Eckart }}$ and $\kappa_{\mu \mathrm{OMT}}$ nearly equal $\kappa_{\mathrm{SCT}}$ over this range, they are not depicted here. 


\section{References}

[1] S. Onishi, S. H. Jo, K. Shoda, P. D. Jo, S. Kato, SAE paper 790501; 1979.

[2] M. Noguchi, T. Tanaka, Y. Takeuchi, SAE paper 790840; 1979.

[3] P. M. Najt, D. E. Foster, SAE paper 830264; 1983.

[4] R. H. Thring, SAE paper 892068; 1989.

[5] J. Zádor, C. A. Taatjes, R. X. Fernandes; Prog. Energy Combust. Sci. 37 (2011) 371.

[6] S. S. Merchant, C. F. Goldsmith, A. G. Vandeputte, M. P. Burke, S. J. Klippenstein, W. H. Green, Combust. Flame 162 (2015) 3658.

[7] J. D. Savee, E. Papajak, B. Rotavera, H. Huang, A. J. Eskola, O. Welz, L. Sheps, C. A. Taatjes, J. Zádor, D. L. Osborn, Science, 347 (2015) 643.

[8] F. Zhang, T. S. Dibble, Phys. Chem. Chem. Phys. 13 (2011) 17969.

[9] M. P. Burke, C. F. Goldsmith, S. J. Klippenstein, O. Welz, H. Huang, I. O. Antonov, John D. Savee, D. L. Osborn, J. Zádor, C. A. Taatjes, and L. Sheps, J. Phys. Chem. A 119 (2015) 7095.

[10] S. Sharma, S. Raman, W. H. Green, J. Phys. Chem. A 114 (2010) 5689.

[11] C. F. Goldsmith, W. H. Green, S. J. Klippenstein, J. Phys. Chem. A 116 (2012) 3325.

[12] L. Vereecken, T. L. Nguyen, I. Hermans, J. Peeters, Chem. Phys. Lett. 393 (2008)

[13] A. Andersen, E. A. Carter, J. Phys. Chem. A 110 (2006) 1393.

[14] G. da Silva, C. Graham, Z.-F. Wang, Environ. Sci. Technol. 44 (2010) 250.

[15] C. F. Goldsmith, M. P. Burke, Y. Georgievskii, S. J. Klippenstein, Proc. Combust. Inst. 35 (2015) 283.

[16] C. Eckart, Phys. Rev. 35 (1930) 1303.

[17] H. S. Johnston, J. Heicklen, J. Phys. Chem. 66 (1962) 532. 
[18] E. Wigner, Z. Phys. Chem. B 19 (1932) 203.

[19] Gaussian 09, Revision A.1, M. J. Frisch, G. W. Trucks, H. B. Schlegel, G. E. Scuseria, M.

A. Robb, J. R. Cheeseman, G. Scalmani, V. Barone, B. Mennucci, G. A. Petersson, H.

Nakatsuji, M. Caricato, X. Li, H. P. Hratchian, A. F. Izmaylov, J. Bloino, G. Zheng, J. L.

Sonnenberg, M. Hada, M. Ehara, K. Toyota, R. Fukuda, J. Hasegawa, M. Ishida, T.

Nakajima, Y. Honda, O. Kitao, H. Nakai, T. Vreven, J. A. Montgomery, Jr., J. E. Peralta,

F. Ogliaro, M. Bearpark, J. J. Heyd, E. Brothers, K. N. Kudin, V. N. Staroverov, R.

Kobayashi, J. Normand, K. Raghavachari, A. Rendell, J. C. Burant, S. S. Iyengar, J.

Tomasi, M. Cossi, N. Rega, J. M. Millam, M. Klene, J. E. Knox, J. B. Cross, V. Bakken,

C. Adamo, J. Jaramillo, R. Gomperts, R. E. Stratmann, O. Yazyev, A. J. Austin, R.

Cammi, C. Pomelli, J. W. Ochterski, R. L. Martin, K. Morokuma, V. G. Zakrzewski, G.

A. Voth, P. Salvador, J. J. Dannenberg, S. Dapprich, A. D. Daniels, Ö. Farkas, J. B.

Foresman, J. V. Ortiz, J. Cioslowski, and D. J. Fox, Gaussian, Inc., Wallingford CT, 2009.

[20] Y. Zhao, N. E. Schultz, D. G. Truhlar, J. Chem. Theor. Comput. 2 (2006) 364.

[21] J. Zheng, S. Zhang, B. J. Lynch, J. C. Corchado, Y.-Y. Chuang, P. L. Fast, W.-P. Hu, Y.-P.

Liu, G. C. Lynch, K. A. Nguyen, C. F. Jackels, A. F. Ramos, B. A. Ellingson, V. S.

Melissas, J. Villa, I. Rossi, E. L. Coitino, J. Pu, T. V. Albu, R. Steckler, B. C. Garrett, A.

D. Isaacson and D. G. Truhlar, POLYRATE-version 2010-A, University of Minnesota, Minneapolis.

[22] J. Zheng, S. Zhang, J. C. Corchado, Y. Chuang, E. L. Coitiño, B. A. Ellingson, D. G. Truhlar, GAUSSRATE-version 2009-A, University of Minnesota, Minneapolis. 
[23] A. Fernandez-Ramos, B. A. Ellingson, B. C. Garrett, D. G. Truhlar, Rev. Comput. Chem. $23(2007) 125$.

[24] I. M. Alecu, J. Zheng, Y. Zhao, D. G. Truhlar, J. Chem. Theory Comput. 6 (2010) 2872.

[25] X. Xu, E. Papajak, J. Zheng, D. G. Truhlar, Phys. Chem. Chem. Phys. 14 (2012) 42044216.

[26] J. A. Montgomery Jr., M. J. Frisch, J. W. Ochterski, and G. A. Petersson, J. Chem. Phys. 110 (1999) 2822.

[27] J. A. Pople, M. Head-Gordon, K. Raghavachari, J. Chem. Phys. 87 (1987) 5968.

[28] C. Moller, M. S. Plesset, Phys. Rev. 46 (1934) 618.

[29] M. Head-Gordon, J. A. Pople, M. J. Frisch, Chem. Phys. Lett. 153 (1988) 503.

[30] J. P. Senosiain , C. B. Musgrave, and D. M. Golden, J. Phys. Chem. A 105 (2001) 1669.

[31] T. N. Truong, J. Phys. Chem. B 101 (1997) 2750.

[32] B. Sirjean, E. Dames, H. Wang, W. Tsang , J. Phys. Chem. A 116 (2012) 319.

[33] H. Hu, T. S. Dibble, J. Phys. Chem. A 117 (2013) 14230.

[34] A. Galano, L. Muñoz-Rugeles, J. R. Alvarez-Idaboy, J. Bao, D. G. Truhlar, J. Phys. Chem A, DOI: 10.1021/acs.jpca.5b07662. 


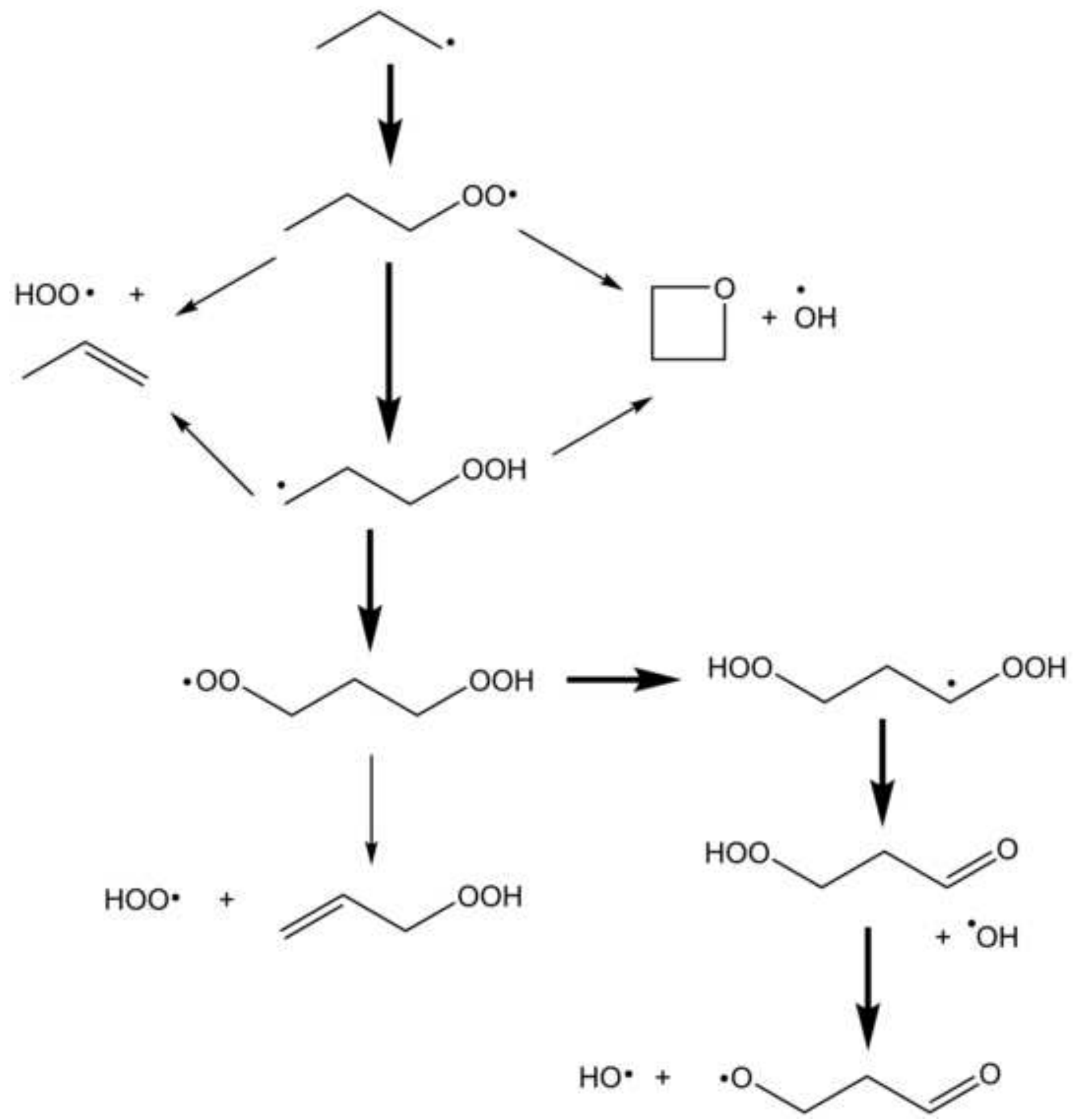



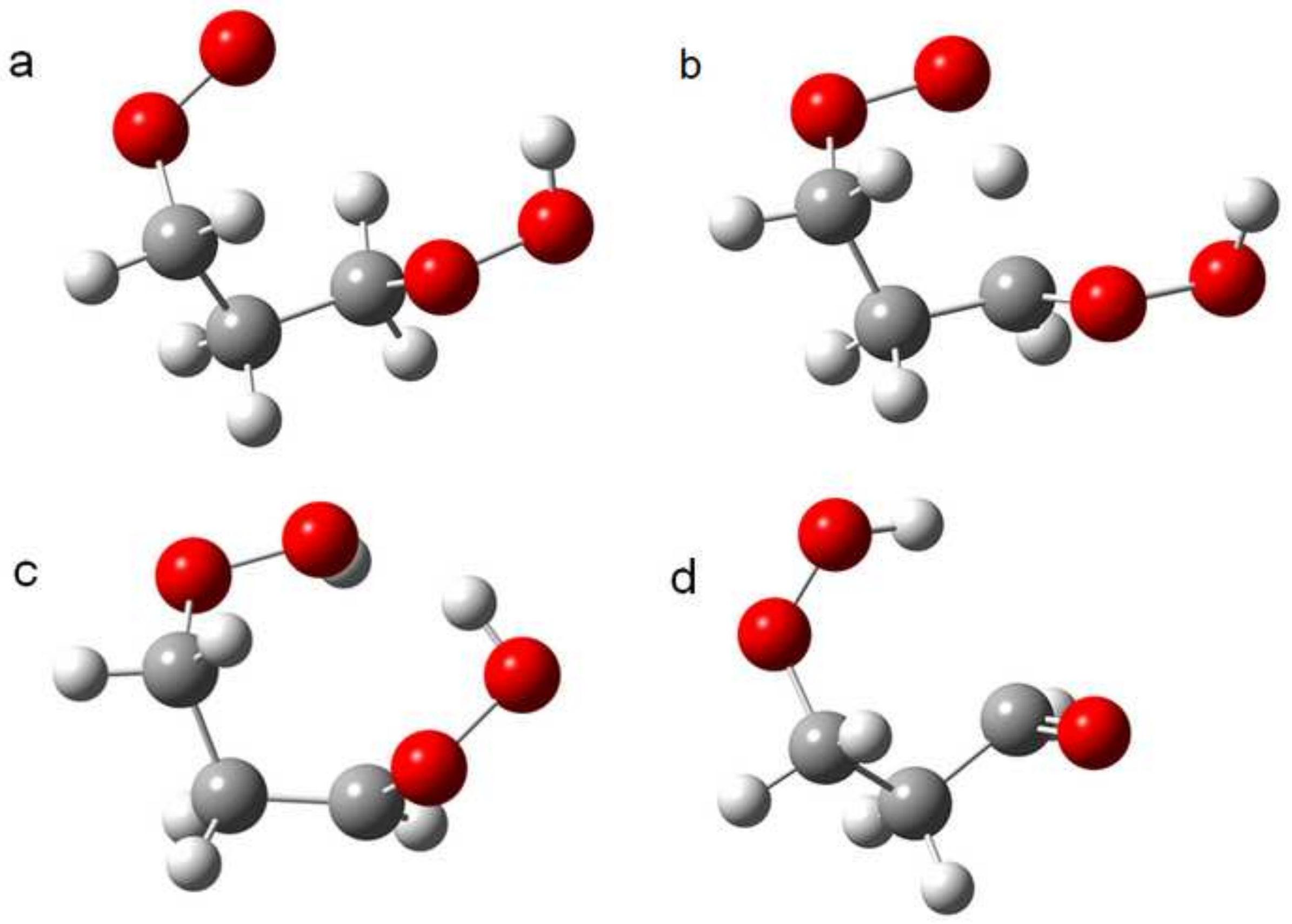


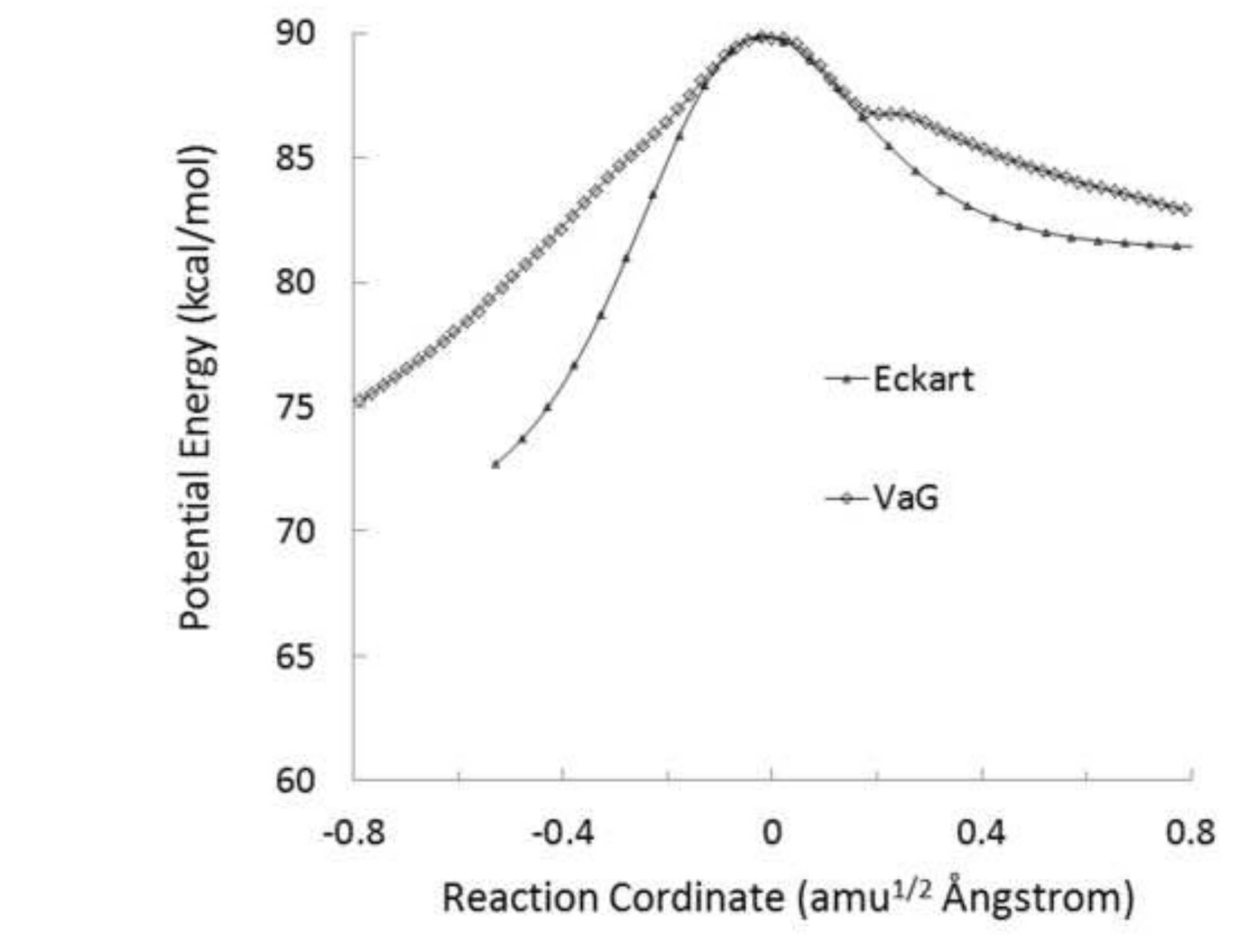




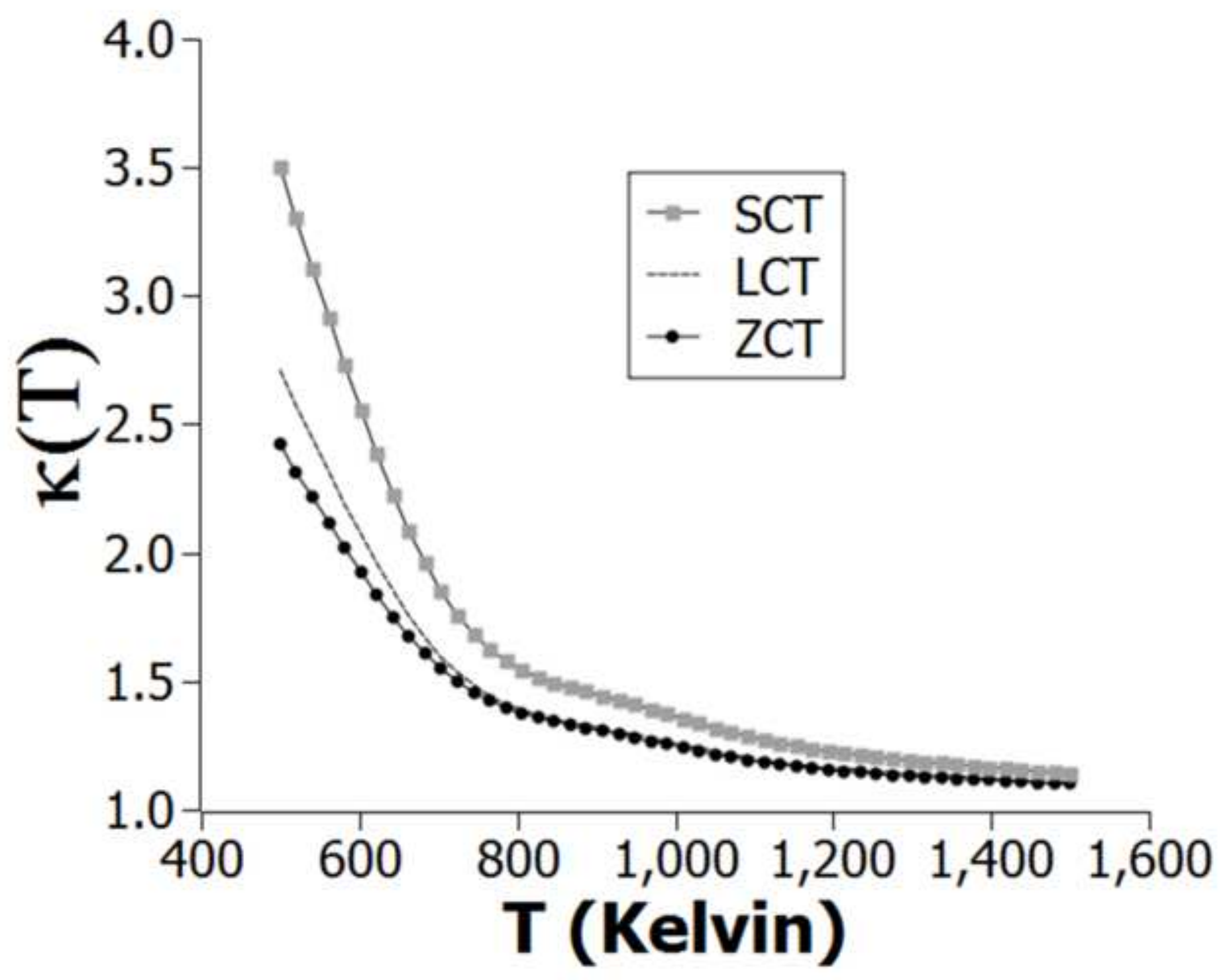




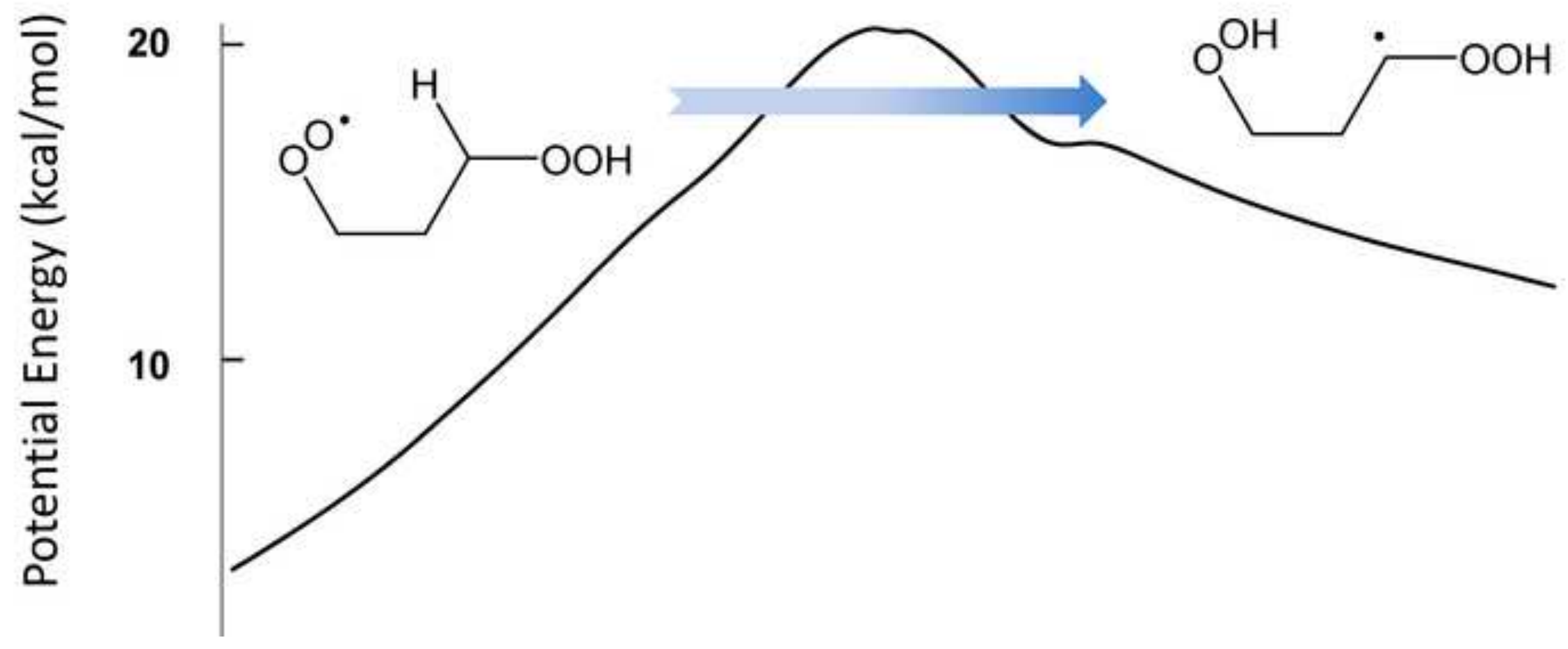

